\title{
ICT Innovations in Traditional Business: A Perspective of O2O Entrepreneurship Strategy in China
}

\author{
G. R. Djavanshir, Xiangyu Li, Kaiheng Luo, Manqi Zhang, Weicheng Pan, and Huang Yawei
}

\begin{abstract}
The Cyber Physical Systems (CPS) or so call the Internet of Things (IoT) is changing the way we shop for products and services. These location and time aware systems have the abilities to determine our presence in a location and send the necessary information to both sellers and buyers of the products or services.

Therefore, along with the rapid developing pace of the Internet of things (IoT), more and more industries and services became possible to reach the public at greater extent. Onlineto-Offline Commerce as an example is capturing the broader global market and changing the way people consume services.

By combining the Internet with traditional industries, China can utilize the advantage of its population and the gap between physical services and retailing sales. Currently, there are mainly three $\mathrm{O2O}$ business model in the market: 020 in Consumer Services, $\mathrm{O2O}$ in Finance, and $\mathrm{O2O}$ in Sharing Economy. After detailed research and study, we have conducted thorough analysis on each particular model, and by providing striking examples of each model to demonstrate the critical role of $\mathrm{O2O}$ model in the development of China's economy and consumer services.

In addition to the current development, we have measured the growth potential of the $\mathbf{O 2 O}$ models and did an eco-systems analysis.
\end{abstract}

Index Term-Information and telecommunications technology (ICT), Online to off-line (O2O), cyber-physical systems (CPS), Internet of things (IoT), Radio-frequency identification (RFID), Global positioning system (GPS).

\section{INTRODUCTION}

The cyber-physical systems (CPSs), also called the Internet of Things (IoT) are changing the way we shop for products and services using cloud-computing technologies [1]. These space and time aware systems use RFID technology to determine our presence in a location and send the necessary information to both sellers and buyers of the products or services. That is, IoT identifies the potential customers through the Internet, and then it uses RFID technology to connect the customers to seller's products or providers of services [2].

Online-to-offline (O2O) is a business strategy that brings potential customers using online channels to physical stores [3].

In fact, $\mathrm{O} 2 \mathrm{O}$ Commerce is a business modus operndi that uses the IoT and mobile systems to drive offline local sales. Starting in 2014, O2O commerce has grown rapidly in China.

Manuscript received August 17, 2016; revised February 8, 2017.

G. Reza Djavanshir is with Johns Hopkins University, Baltimore, USA (e-mail: rj@jhu.edu).
As many executives around the world have discovered, China's e-commerce markets are perhaps the most dynamiceven frenetic-on the planet. Nowhere is this dynamism more evident than in the burgeoning online-to-offline sector, where start-ups use apps, email, and other digital tools to entice shoppers to buy from physical stores or to purchase real-world services [4].

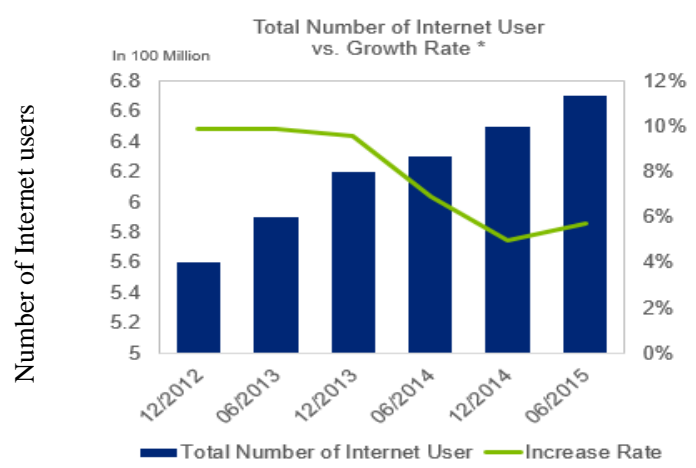

Fig. 1. Total number of Internet user as a function of growth rate.

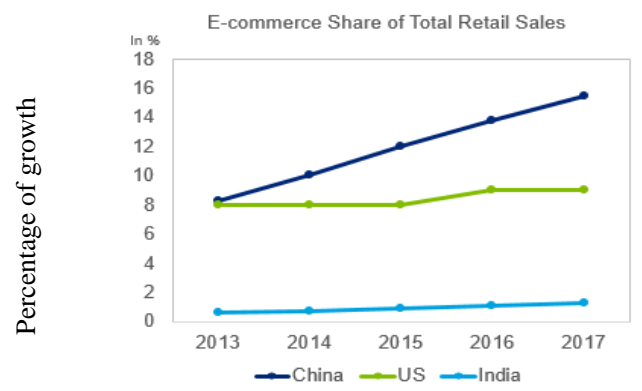

Fig. 2. Ecommerce Share of Total Retail Sales, from 2013 to 2016

The O2O's success in the Chinese market strongly associates with the China's socio-economic system. According to the Fig. 1, the number of the Internet users in China has shown strongly increased rate in the past years [5]. By June 2015, China has had more than 670 million Internet users; it is a number that doubled the total population in the United States. From the Fig. 1, we can also observe that the Internet user's increase rate experienced a sharp decrease between 2013 and 2014. There are many reasons behind this drop. One of the most direct factors is the decreasing in China's young population. China instituted its "one child policy" in 1970 with a purpose of reducing its increasing population and to ease its social-economic burden. Besides the large Internet user base, another advantage that facilitates the popularity of $\mathrm{O} 2 \mathrm{O}$ in China is the increasing share of e-commerce in Chinese total retailing sales. According to the Fig. 2, Ecommerce Share of Total Retail Sales, from 2013 to 2016, China was able to keep the double-digits increase in e-commerce sales among the total 
retailing sales. And it is likely to keep this ability in the future according to the estimation [6]. Compare to US and India, China's e-commerce share grows rapidly in the total retailing sales. This also provides the key fundamental factors to the success of $\mathrm{O} 2 \mathrm{O}$ strategy in the Chinese market.

\section{A. O2O Business Models}

$\mathrm{O} 2 \mathrm{O}$ business models are also being developed and implemented by individual citizen and businesses, thereby enabling the attraction of a wider and strong customer base and hence greater revenues [7].

As we have mentioned before, the Online-to-Offline $(\mathrm{O} 2 \mathrm{O})$ is a renovated business strategy that utilizes technology to connect the online customers to an offline business. If we put this model into a triangle diagram with Users, $\mathrm{O} 2 \mathrm{O}$

Business Model and Offline Business on each corner, we will see a figure similar to Fig. 3. On the left bottom corner, Internet users and customers provide demand and traffic to the $\mathrm{O} 2 \mathrm{O}$ Business Model on the top. Then, the $\mathrm{O} 2 \mathrm{O}$ business model converts the customer's demand into business opportunities and delivers those opportunities to the offline business. Mobile IT technology and traditional goods and services combined together become the core and heart of this strategy. The purpose of adopting this model provides larger customers base to the offline business, offers better shopping experience and easier access to the service and products consumers.

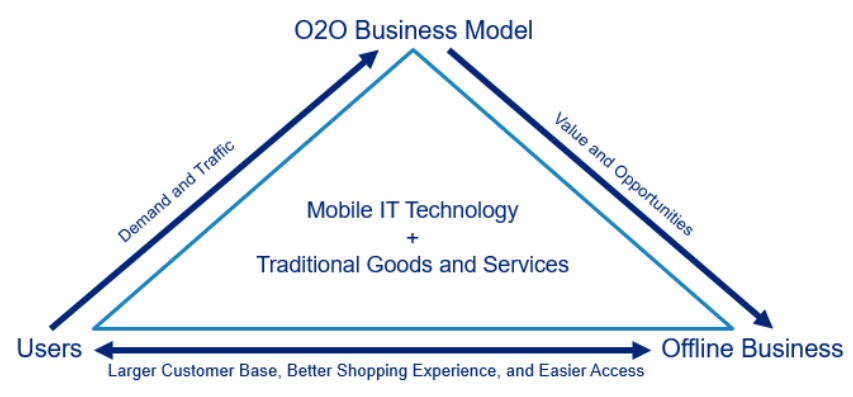

Fig. 3. O2O Business model.

\section{B. O2O in Other Countries}

Andrew Yan-Tak Ng [8], the Chief Scientist at Baidu Research and professor in the Stanford University, he has commented the following in his Google Plus account to express his vision of seeing the $\mathrm{O} 2 \mathrm{O}$ business model becomes popular world widely. "I'm seeing internet services in China develop in a very different direction than the US. China's biggest trend is $\mathrm{O} 2 \mathrm{O}$, meaning using your mobile device to discover and buy local services, such as laundry, a car wash, booking a hairdresser, hiring a tennis coach, etc. These types of $\mathrm{O} 2 \mathrm{O}$ services are pervasive, affordable and routinely used by a very broad segment of the population. I hope the development of $\mathrm{O} 2 \mathrm{O}$ accelerates in the US too" [8]. Our purpose in this research paper is to explain the $\mathrm{O} 2 \mathrm{O}$ business strategy by providing three $\mathrm{O} 2 \mathrm{O}$ business model: $\mathrm{O} 2 \mathrm{O}$ in Consumer Services, $\mathrm{O} 2 \mathrm{O}$ in Finance, and $\mathrm{O} 2 \mathrm{O}$ in Sharing Economy. We will conduct thorough research on each of the model and provide examples to better illustrate how $\mathrm{O} 2 \mathrm{O}$ model play positive roles in those transitional industries. We will conduct the eco-system analysis to assess the factors that cause O2O's success in China. Finally, we will use those factors to provide an estimation of O2O's development in US and India.

\section{O2O IN CONSUMERS SERVICES}

Consumer service industry involves the provision of service to business as well as end consumers. As its shown in Fig. 4, it contains several services, such as food services, entertainment, traveling, auto repair, health cleaning services laundry, etc. There are no goods produced in the consumer industry since the primary industry extracts the raw materials and the second industry manufacture the products. In other words, the consumer service industry is about creating a connection between service providers and consumers.
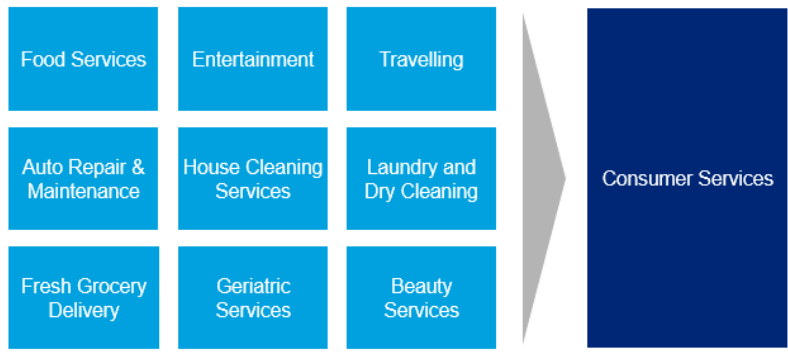

Fig. 4. Differed Consumers services

\section{A. Pain Points of Current Consumer Service Industry in China}

In China's Current Consumer Service Industry, information barrier constitutes one of the most serious pain points. Specifically, information barrier means the barriers to prevent a free exchange of information on both service providers and consumers. For the consumer side, it includes customers contact information, distribution, buying power, and time availabilities. For the service providers the information barrier represents service providers' availabilities, service quality, and information about the market and their competitors. Because of the information barrier that prevents the free exchange of information between consumers and services providers, in China's consumer service industry is facing many difficulties.

Additionally, due to the information barrier, service providers have limited ways to increase customer base and there is a lack of customers' feedbacks. The increasing competitions in the industry and lack of industry standards also bring out the problems. And the customers are facing a lot of problems such as limited selection of service providers, limited access to other customers' feedbacks, inconsistency of service quality and high turnover rate of service providers.

\section{B. Applied O2O Case: The Case of Chinese Leading Food Delivery O2O-Ele.me}

Ele.me is a Chinese Leading Food delivery company. In April 2009, the company was founded in Beijing, China. After one and a half year, it could process more than 1,000 food orders per day and became the largest food $\mathrm{O} 2 \mathrm{O}$ Company in China in December 2011 with 10,000 orders 
per day. One year later, its average daily sales were more than 3 million RMB. Through November 2013 to January 2015, the company has received 25 million USD, 80 million USD. In April 2016, the company has Secured 1.6 billion USD on private equity [9].

After reviewing the Ele.me official website, we have generated an operational flow Fig. 5 as shown on the left. For food service providers, they publish their product and service information on the ele.me. Then, ele.me utilize its ICT technology to process online orders, distributes products (food) through its local delivery networks, and creates a platform to facilitate the communication between food providers and customers. For the customers, ele.me's system could provide a one-stop shopping experience including, food ordering, food delivering, and food evaluation based on their web site (ele.me) helps customers to reach a greater base of food service providers, in other words, a greater selection of service. On the flip side, by joining the platform, food providers could easily expand their customer's base without heavy financial burden on advertising cost. Ele.me's profits come from two parts. One part is the loyalty fee that collected from the food providers on a monthly or yearly basis. Another part is the transaction fee collected from customers during the online transaction process. This business model is a prime example of how O2O strategy adopts IT and Mobile technology to tackle the information barrier in a traditional business.

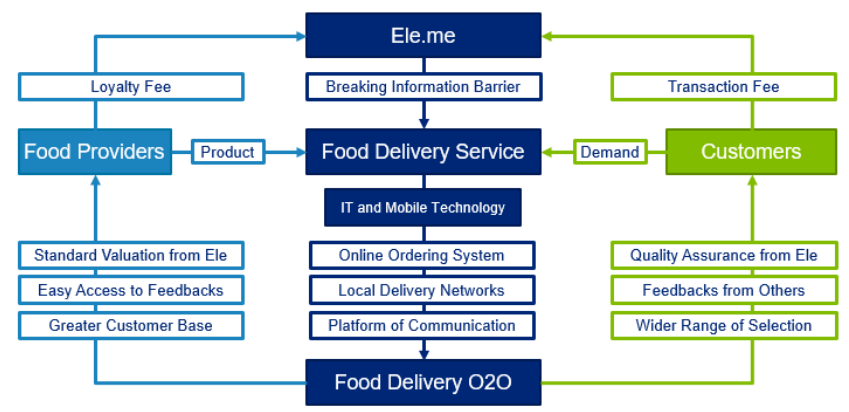

Fig. 5. Ele.me operational workflow.

C. Eco-systems (Strengths, Weaknesses, Opportunities, and Threats) Analysis

For the strengths, Ele.me is the biggest food delivery O2Oin China with $40.07 \%$ market share. Also, ele.me has strong ability to raise capital and is able to keep this advantage in the future. For the weakness, the company has no core competence and it relies heavily on food providers so the company has to maintain business with them in order to keep the business running. For its opportunities, the PE (private equity) and VC (venture capital) investors hold positive opinions on $\mathrm{O} 2 \mathrm{O}$ business model since it fits consumers' shopping behavior of the new generation. Their $\mathrm{O} 2 \mathrm{O}$ business strategy breaks the information barrier and provides easy access for both parties. At the same time, development of ICT and mobile technology provides huge potential for $\mathrm{O} 2 \mathrm{O}$ food delivery business. There are also a lot of threats for Ele.me and its $\mathrm{O} 2 \mathrm{O}$ business model. First, the strategy of burning cash does not develop consumers' loyalty, so the consumers might change to other service providers if they have a more attractive discount or some other promotions. Second, the lack of government regulation on $\mathrm{O} 2 \mathrm{O}$ food delivery becomes a huge variable for the food delivery industry, the future of this industry is unpredictable. What's more, the new business model will make a shift in investors' interest and intensive competitions from tech giants, such as Baidu, Alibaba, and Tencent (BAT) tends to be huge threats to the company.

\section{Applied O2O Case: The Case of Chinese Household Service $\mathrm{O} 2 \mathrm{O}$ - Ayibang}

Ayibang is a company that provides house cleaning, appliance service, and laundry\& dry cleaning service. According to its official website, Ayibang's business operation flows the Fig. 6. Specifically, customers send job demand to the Ayibang server and then the server pass the request to the household service providers. Ayibang provides customer base and marketing strategy, service training and process management to household service providers. Customers can get the information of reviews\& evaluations, do the secure background check and get free service insurance from Ayibang.

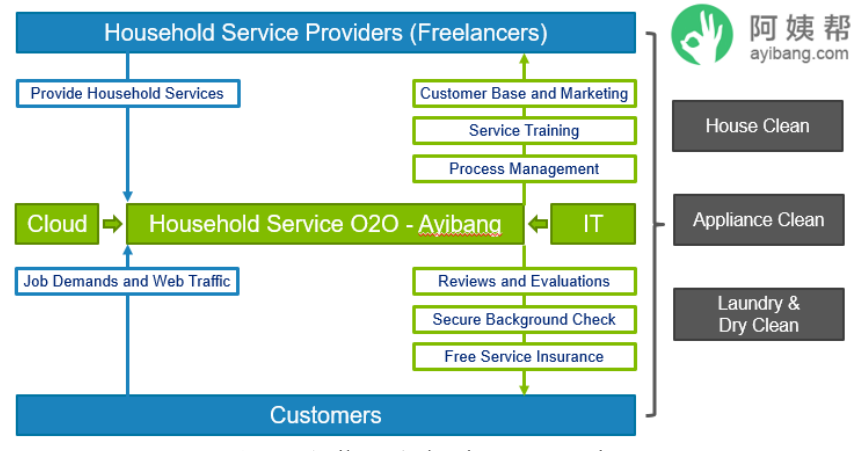

Fig. 6. Ayibang's business operation.

For the strengths, Ayibang's founder and management team has a rich experience in emerging technology and traditional operations and are able to raise capital and to generate good cash flows. Furthermore, the company has already recruited more than 30,000 freelancers. For the weakness, the variation on freelancers and the limited resources are the limitation of their development. Because there is no tech giant has entered this industry yet and the growing need from the market, the company has the opportunities they need to be successful in its business industry. At the same time, the $\mathrm{O} 2 \mathrm{O}$ model on household service fits consumers' shopping behavior of the new generation. The threats that the company is facing are, first, the increasing labor cost and competitions from other companies in China. Second, the new robots with house cleaning function are taking the company's market share. Then, the upcoming new business model will make a shift in investors' interest.

\section{O2O IN FINANCE}

While $\mathrm{O} 2 \mathrm{O}$ is trying to integrate the brick-and-mortar retail model with e-commerce and has definitely reshaped the traditional payment method, this part of the paper focuses less on closing deals online. Instead, we will look into how $\mathrm{O} 2 \mathrm{O}$ platform affects and cooperates with financial institutions and therefore provides new financing and investment options for enterprises. 
Usually, companies work through financial institutions as intermediaries to achieve their financial goals. However, online payment becomes a game changer because it introduces the form of peer-to-peer lending (P2P), without the interference of financial institutions. P2P simply allows lenders and borrowers to communicate and make transactions [10]. However, it didn't take long before people realized how risky this would be. While P2P breaks the traditional time constraint and location constraint - for example, the closest bank near you place opens from 9 am to $4: 30 \mathrm{pm}$ from Monday to Friday but now you can deal with your wealth $24 \times 7$ as long as you have access to the Internet, it also significantly impairs the security banks can provide. In addition, private lenders may never have access to a number of capitals banks own. In fact, this is where financial institutions find to enter the $\mathrm{P} 2 \mathrm{P}$ market. Banks partnered themselves with $\mathrm{P} 2 \mathrm{P}$ platforms and became involved in loan lending online. With the participation of banks, institutional investors were soon attracted. In 2014, P2P in the United States alone issued more than 5 billion of loans and this number is expected to grow up to 150 billion or more by 2025 according to PWC [11].

Pairing with $\mathrm{P} 2 \mathrm{P}$ platform, traditional financial institutions are able to bring their services from offline to online and then from online to offline again in terms of specific consulting services.

For example, an investment meeting scheduled after review of investment goal and risk factors online will be so much more efficient than the old days. With the assistance of the IoT, investment decisions can be made typically from 2 to 5 days now. Together with $\mathrm{P} 2 \mathrm{P}$ and $\mathrm{O} 2 \mathrm{O}$, both clients and traditional financial institutions are able to break time constraint, location constraint and transparency constraint since information is more accessible now.

\section{A. Applied O2O Case: Rong 360}

A typical example of $\mathrm{O} 2 \mathrm{O}$ financial platforms is Rong 360 in China whose motto is straight "Search, Compare, Contact". Rong 360 is a leading provider of customized financing and loan information in China specializing in small loans less than 50,000 CNY (approximately 8,000 USD). In 2015, it launches a big data risk analysis called “Myth (Chinese: 天机)” to better evaluate the borrowers. With this model, Rong 360 aims to exam the applicant in 10 minutes and gives the loan on the same day by the fastest.

The search function enables users to search loan and financial products from more than 10,000 banks and lending agencies, which covers $95 \%$ of financial products in the market. The so-called "Compare function" also enables customers to review the performance history of individual products and provides a side-by-side comparison among different products. Finally, the "Contact function" brings the business offline by bridging between the lender and the borrower with financial experts from Rong 360 24x7 available.

Rong 360's model is in common use for loan matching platforms. Borrowers and investors find their desired counterparts by their evaluation and advice from the specialists. Reliable information is the key to this model and it requires an intensive understanding of finance from its participants.

\section{B. Applied O2O Case: Lufax}

Shanghai Lujiazui International Financial Asset Exchange (aka, Lufax), which is an online Internet finance marketplace in China founded in 2011 under the parent company of China Ping An Group. Unlike Rong 360 who matches borrowers and lenders and works as intermediary and counsel, Lufax takes more responsibility in the financing process. They collect funds from investors beforehand and allocate them to the borrowers with a predetermined interest rate regardless of the financial status of the borrower. When the money is paid back, Lufax takes $4 \%$ commission and delivers it back to the lender. Additionally, Lufax works as a guarantor to the investors [12].

Online payment transaction volume in China from 2009 to 2019 (in billion yua This statistic shows the online payment transaction volume in Chin from 2009 to 2014, with a projection u 2012, the online payment transaction volume in China amounted to 3.7 trillion yuan.

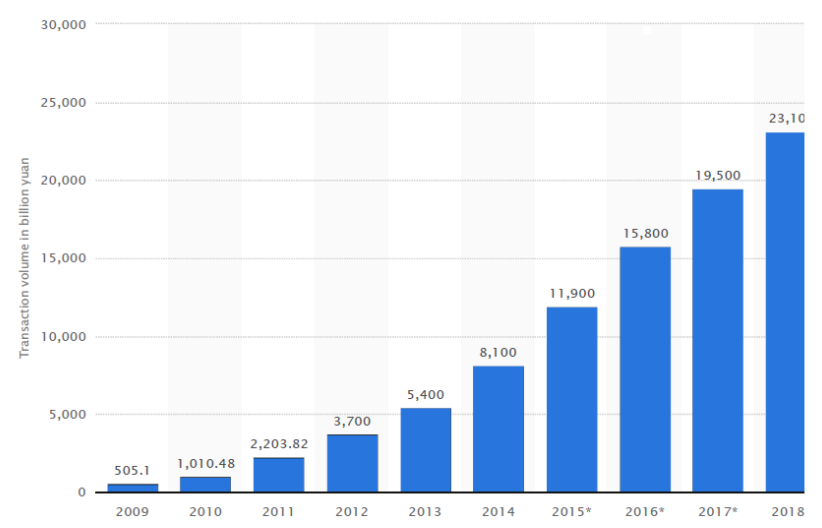

Fig. 7. the growing trend in the number of online transactions in Chinese economy.

Intuitively, the risk assessment process for Lufax is more complex. The screening process of the lenders includes the pre-screen from Lufax and the evaluation from its underwriting company to guarantee timely payments. In a rating announcement by Chinese top financial institutions in October 2015, Lufax gained triple-A ratings, being the only one in P2P platforms. The centralized wholesale model relies on the judgment of investor but has a much stricter requirement on lenders.

Both Rong 360's model and Lufax's model are popular in China now while one offers abundant information and the other one provides steady payment.

\section{The Roles of ICT in O2O Finance}

ICT serves as the backbone of $\mathrm{O} 2 \mathrm{O}$ finance. Figure 7 shows the growing trend in the number of online transactions in Chinese economy. One of the reasons why $\mathrm{O} 2 \mathrm{O}$ finance is burgeoning in China is the fast growing Internet expansion and ICT infrastructure. Based on our research, the following chart shows the forecasted online transaction volume in China. As of 2015, the amount already surpassed 13 trillion and by 2019 , that number is foreseen to be larger than 23 trillion [13].

The growing Internet access increases accessibility of financial products and services by a huge margin. ICT, and IoT together allow participants to track their financial activities anytime, anywhere and with the right authorization, by anyone. Technologies are redefining 
finance in the sense that they significantly reduce costs, both in terms of money and time, increase customer bases and improve service quality.

While the revenue that ICT could bring is clear, there are also some challenges companies are facing. For example, a start-up company in consumer services now needs to develop their own applications to effectively reach its potential customers and collect payments more easily, which can take up a large portion of its initial cash flow and capital investments. Also, technology breakdowns and uncertainties could also be a risk factor companies are exposed to. However, overall ICT and IoT are bringing revolutionary changes to the way people finance and it is important for companies to make the best use of it.

\section{Porters' Five Forces Analysis on O2O Finance Industry}

Michael Porter has identified five competitive forces that shape a business's and an industry's strategy [14].

After the review of the market, we conduct a Porter 5 analysis of the $\mathrm{O} 2 \mathrm{O}$ finance business:

Threats of new entrants are estimated to be low because there are high barriers of ICT technology required to build a comprehensive $\mathrm{O} 2 \mathrm{O}$ platform and even if that is feasible, there are high barriers to obtaining a license from the government. If all the registration goes smoothly, it will be another high barrier for a new company to conquer to reach abundant customers.

Threats of substitutes are also not high now because traditional counter services by the banks are not comparable in both customer turnover rates and capital flows to $\mathrm{O} 2 \mathrm{O}$ platforms.

Both bargaining power of suppliers and buyers are low now because no single lender or borrower has enough power to bargain with an established large O2O company. For sure, institutional investors have power in this game and with the business model getting more mature, we will see more fund suppliers have the power of disclosure in this model in terms of commission they are willing to pay and interests they require.

At last, with all the other threats being relatively insignificant now, the rivalry among existing competitors are in fact really high since the business strategy are almost identical and replicable within the industry and so far no single company has seemed to develop a distinctive pattern that obviously outshine the others. We expect that the high competition within $\mathrm{O} 2 \mathrm{O}$ finance will continue for a while until the central banks want to consolidate the industry and deliberately reduce game players.

\section{O2O IN SHARING ECONOMY}

Sharing economy allows individuals act as an ad hoc service providers, car-hire firm or hotel services as and when it suits them [15].

The sharing economy matches people who want to share their assets online, utilizes the unused resources to fulfill customers' need. It's nearly impossible to come up with a solid definition of sharing economy because of its great diversity activities. But we can basically divide it into the following four categories:
(1) Recirculation of goods

(2) Increased utilization of durable assets

(3) Exchange of services, and

(4) Sharing of productive assets [16].

Most of the sharing economy being used nowadays is the second category. Companies create a platform to facilitate using durable goods such as apartments and private cars more intensively. Companies make use of IoT to better serve consumers. Those companies that don't need to own those assets; they just provide a platform, providing a trusted place for customers to exchange their resources using mobile applications. This business strategy is $\mathrm{O} 2 \mathrm{O}$ that has spread into different areas. In the transportation sector, these include ride services like Uber and Lyft. In lodge part, Airbnb allows an individual to share their rooms or apartments to travelers.

\section{A. Example in O2O in Sharing Economy: Uber}

Uber was founded in 2009. It's a high-tech company that connects the transportation industry with technology via an IoT (mobile application). It offered services in over 250 cities in 58 countries by 2015 . There are many reasons why Uber success. It has several advantages beyond lower fares. However, the firm also evokes some contrasting emotions, especially in China. Therefore, Uber should make some changes to expand the market in China.

\section{B. Eco-system's Analysis of Uber}

Strength-Uber provides a good user experience. It gives passengers the possibility to grab a taxi no matter what the current location is, and shows the price you will pay before taking the taxi. Besides, it connects with Google map to track the entire route of the ride. All of these activities could be conveniently achieved as long as you have a smartphone and an Uber App.

Additionally, it's a well-recognized brand; lots of passengers from different countries have used Uber with good feedback. Because of the high valuation of it, many people are ready to invest on it, to better develop and organize the whole system.

The service is based on direct client-to-driver interaction, so there is a dual rating system boosts trust and safety.

Weaknesses-Uber also has some weaknesses that may prevent it from expanding further in China. Since traditional taxi services are under the obligation of vehicle departments with constraints of legislation and regulations, and Uber is famous for skirting regulations. This will raise the security problem, for both passengers and drivers. Besides, there are privacy concerns. Uber records where the customer gets the taxi from, also it notes where s/he goes, if hackers attack the database of Uber, they will get lots of private information such as passengers' credit card number, phone number, and route history.

Opportunity-Since the relationship between drivers and company is relatively weak during the competition between traditional competitors, it's important to keep both Uber drivers and costumers satisfied. According to the statistics posted by Uber, the growing number of Uber drivers will cause a reduction in the Estimated Time of Arrival (ETA), which can satisfy more costumers and make the service 
more profitable for drivers.

Besides, Uber can cooperate with Chinese technology giant-Baidu, to increase the publicity and attract more people to join and use Uber.

Threats-However, Uber still needs to find other ways to keep and build new competitive advantages over other competitors. Despite its innovative design, the idea can be easily copied. Also, some new legal regulations in China may restrict Uber's expanding; Problems with local authorities may lead to fines, which lead to bad public relations.

\section{GROWTH POTENTIAL MATRIX OF O2O INDUSTRY}

By now, we have explained the $\mathrm{O} 2 \mathrm{O}$ business strategy in three different industries, the consumer service, the finance, and the sharing economy. In order to measure the growth potential of $\mathrm{O} 2 \mathrm{O}$ in these three industries, we add a vertical factor called the "Level of Technology Advancement" and the horizontal factor named "Level of Market Fragmentation" (Figure 8). The level of technology advancement measures the ICT and IoT technologies that $\mathrm{O} 2 \mathrm{O}$ business strategy has adopted in this industry. In other words, it represents the technology barrier to implementing the $\mathrm{O} 2 \mathrm{O}$ business strategy in this industry. The level of market fragmentation, on the other hand, is a reflection of competitions in the market. For O2O in Consumer Service, ICT and IoT technologies provide functions, such as information publishing, communication, and online ordering system. Depending on the specific tasks, the ICT advancement in consumer service industry generally falls into the low or medium category. For $\mathrm{O} 2 \mathrm{O}$ business strategy in financial industry, the level of technology can be anywhere between low and high. Generally speaking, if the company focuses primarily on financial product advertising and there are no direct transactions involved, the level of technology advancement tend to be low. If the company involves online transactions with a large amount of money involved and investment management, due to the security reasons and the complexity of the underlying technologies, the level of technology advancement tends to be high. In sharing economy industry, we assume the level of technology advancement is medium to high. This is because the $\mathrm{O} 2 \mathrm{O}$ business in sharing economy has widely adopted technologies such as Global Positiong System (GPS) and real-time monitoring. These technologies also constitute a high level of tech barrier for new companies entraning of $\mathrm{O} 2 \mathrm{O}$ businessin sharing economy. From the perspective of market fragmentation, since there are so many providers in various subsectors of consumer service industry, we assume that $\mathrm{O} 2 \mathrm{O}$ in consumer service industry has high to medium level of market fragmentation. Similar to the technology advancement, depending on the specific services and business contenxt, the market fragmentation of $\mathrm{O} 2 \mathrm{O}$ in finance could be anywhere from low to high. In the sharing economy, the market fragmentation is relatively low or medium. The reason behind this is that sharing economy is still new to the market. In addition, its development faces strong conflicts with government regulations as well as the legacy business operators. Therefore, we see a result of low to the medium of market fragmentation in this area. As we have explained in the beginning of this section, the technology advancement level represents the technical barrier for the new entries. The market fragmentation is a fair representation of the market competition level. As a result, $\mathrm{O} 2 \mathrm{O}$ business strategies in sharing economy have higher than average technical barrier to stop the new entries and lower than average's competition. Therefore, we say that $\mathrm{O} 2 \mathrm{O}$ in sharing economy has a greater growth potential among the three $\mathrm{O} 2 \mathrm{O}$ services.

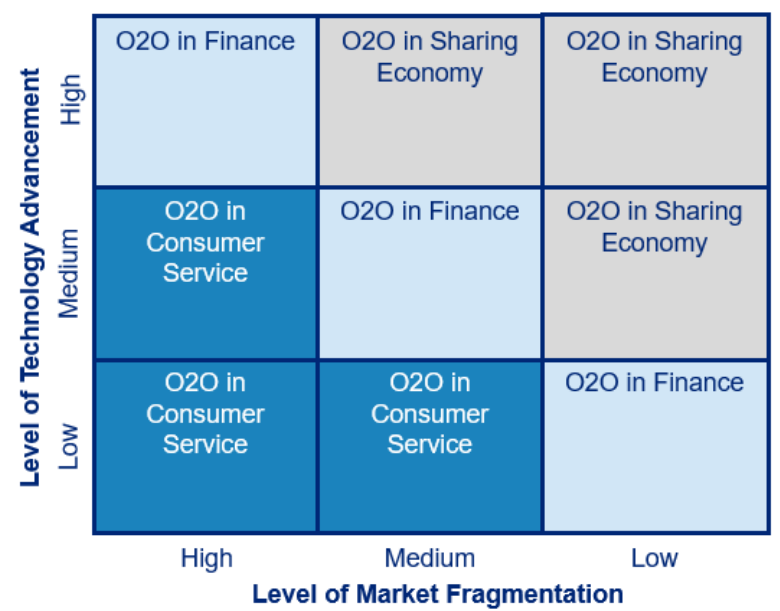

Fig. 8. Level of Market Fragmentation in China.

\section{VI.ECO-SYSTEMS FACTORS ANALYSIS}

\section{A. Eco-system's Factors' Analysis of $\mathrm{O} 2 \mathrm{O}$ in China}

So far, we have conducted an analysis of different kinds of $\mathrm{O} 2 \mathrm{O}$ businesses and we have used multiple business strategies to assess those companies' internal factors to make them successful in China. In this section, we will shift our perspective to the external environment. We will use political/legal, economic, socio-cultural, and technological factors analysis to examine how would the market in China supports the $\mathrm{O} 2 \mathrm{O}$ businesses' rapid growth. Political/legal, economic, socio-cultural, and technological factors or so called PEST analysis is an ecosystem's scanning tool created by Harvard professor Francis Aguilar in 1967 [17]. We will examine each of the factors in details and explain how these factors combine together to facilitate the $\mathrm{O} 2 \mathrm{O}$ business growth in China.

\section{B. Eco-system's Analysis-Political/legal Factors}

In the political part, China's national strategy on economic structure reformation becomes a prime support of the $\mathrm{O} 2 \mathrm{O}$ businesses' growth in China. This national strategy also performs as a top guideline to lead the development of China's tertiary industry, where many of the $\mathrm{O} 2 \mathrm{O}$ businesses belong. Besides the national strategy, both of the Chinese central government and local governments have announced a series of policies to facilitate the development of ICT infrastructure and services. Since O2O business strategies heavily rely on the Internet IoT technologies, these policies also played positive roles for $\mathrm{O} 2 \mathrm{O}$ industry in China. Besides this, since China is a developing country, there is a lack of government rulings on industry details. This leaves the $\mathrm{O} 2 \mathrm{O}$ business operations legal freedom to create innovated business model with less legal constraints. 


\section{Eco-system's Analysis - Economic Factors}

In economic factor analysis, the growing trend of $\mathrm{O} 2 \mathrm{O}$ businesses in China fits the growing of China's economy as a whole. Specifically, since any $\mathrm{O} 2 \mathrm{O}$ business strategy focuses on providing services to end users, the growing purchasing power of population plays positive roles in O2O's growth in China. In addition, China's open policy attract many foreign investors each year, the mature financing system ensures the $\mathrm{O} 2 \mathrm{O}$ businesses the have ability and possibility to raise capital - which constitutes the key for many start-ups and new business to success in the initial stage.

\section{Eco-System'S Analysis - Socio-Cultural Factors}

Chinese active role in today's global economy has changed socio-cultural conditions. This shift of sociocultural factors provides an ideal external environment of the $\mathrm{O} 2 \mathrm{O}$ business development. For instance, in many Chinese cities with the high population, there are strong demands for $\mathrm{O} 2 \mathrm{O}$ services. Also, since a combination of China's large number of educated population creates good opportunities for $\mathrm{O} 2 \mathrm{O}$ businesses. In addition, the Chinese modern ICT infrastructure, fast life pace in working families, as well as the shopping behaviors shifts due to the growing of younger generation all facilitate the development of $\mathrm{O} 2 \mathrm{O}$ businesses in China.

\section{E. Eco-system's Analysis-Technological Factors}

On the technological factors side, China has many advantages and those advantages have been widely adopted by $\mathrm{O} 2 \mathrm{O}$ business strategies to support their growing trends. Specifically, China is one of the countries that have the highest rate of mobile devices and the Internet service coverage. This is the result of China built a vibrant ICT infrastructure. Also, China has sufficient number of ICT professionals in its labor market and the cost of implementing ICT technology is relatively low compared to many other countries with similar size and population.

\section{F. Assessing the O2O Business Opportunity in China with in US and India by Eco-systems Analysis}

The eco-systems analysis provides us how China's external factors facilitate the development of $\mathrm{O} 2 \mathrm{O}$ business models. If we use these factors as a guideline to cross-match with two other competing countries' (United States and India) national condition, it will give us an estimation of where the $\mathrm{O} 2 \mathrm{O}$ businesses will advance in the foreseeable future.

Here, we have selected two target countries based on the factors, such as economic size, population, and infrastructure. As we can see from the below diagram, in the political factors, India seems to share more similarities with China. However, it doesn't have the national strategy on its economy to grow $\mathrm{O} 2 \mathrm{O}$ businesses. In the economic factor side, United States share more similarities with China with an exception of growth rate. On the Social factor, both United States and India are quite different than China. However, the slow development of infrastructure services and people's working and living behavior in India clearly constitute social barriers for $\mathrm{O} 2 \mathrm{O}$ to develop in India (Fig. 9 and 10). In technological side, the United States definitely beat India and shares more similarities with what China has right now. As a result, we conclude that even though United States doesn't fit perfectly with the factors that we have drawn out from the PEST Analysis, compare to India, it is more likely to support and facilitate the growing and development of $\mathrm{O} 2 \mathrm{O}$ businesses.

\begin{tabular}{|c|l|c|c|}
\hline P & Factors to Develop O2O & USA & India \\
\hline P & National strategy on economic structure reformation & \\
\hline P & $\begin{array}{l}\text { Government Regulation to support the development of Internet of } \\
\text { Service }\end{array}$ & \\
\hline P & Lack of government rulings on industry details & 0 & \\
\hline E & Factors to Develop O2O & USA & India \\
\hline E & Growing buying power of general population & & \\
\hline E & Mature financing system & & \\
\hline E & High growth rate of the country's economy & & \\
\hline E & Increasing numbers of the private company in the market & & \\
\hline
\end{tabular}

Fig. 9. Political and Economic factors contributing $\mathrm{O} 2 \mathrm{O}$ Business in India.

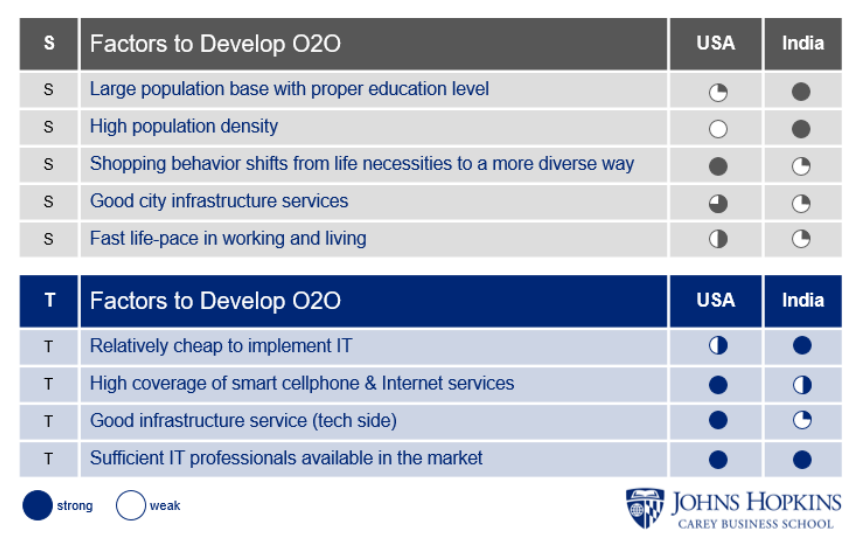

Fig. 10. Social and Technological factors contributing O2O Business in India.

\section{CONCLUSION}

Regardless of the type of $\mathrm{O} 2 \mathrm{O}$ model, the core value of this business strategy is to create economic benefits by providing services. For each country, the influence of external eco-system is just as inevitable as the internal factors. However, the advancement of ICT and emerging IoT technologies with appropriate regulations and public policies will eventually improve the way we live, shop, and obtain services.

\section{REFERENCES}

[1] E. Simmon, S. K. Sowe, and K. Zettsu, "Designing a cyber-physical cloud computing architecture," IEEE, IT Professional, pp. 40-45, May/June 2015.

[2] M. Miller, "The internet of things," Que Publishing Inc. Indiana Polis, Indiana, 2015.

[3] P. Burke, "The benefits of online-to-offline commerce," CIO Insight, 2016.

[4] W. Zhang, "Behind China's runaway offline-to-online commerce," McKinsey Quarterly, December 2015.

[5] Wind Information Terminal, "Total number of internet users vs growth rate," Beijing, China, , 2016.

[6] Wind Information Terminal, "E-commercd share of total reail sales," Beijing, China, April 30, 2016

[7] K. Mervyn. (2015). Entrepreneur. Kieran Mervyn. [Online] Available: https://www.entrepreneur.com/article/242267

[8] Y.-T. N. Andrew. (August 6, 2015). Baidu hopes to clean up with O2O laundry firm," Retrieved from Google Plus. [Online]. Available: https://plus.google.com/113710395888978478005/posts/bKwKwW4 jMAP 
[9] Crunchbase. (2016, April 30). Ele.me. Retrieved from Crunchbase, [Online]. Available: https://www.crunchbase.com/organization/eleme

[10] Athwal, Nav. "The disapperance of peer-to-peer lending," Forbes. Forbes Magazine, 19 May, 2016.

[11] Peer Pressure: How Peer-to-peer Lending Platforms Are TransForming the Consumer Lending Industry. (Feb. 2015). PWC, [Online]. Available: http://www.pwc.com/us/en/consumerfinance/publications/peer-to-peer-lending.html

[12] Z. Faux, "Most Chinese peer-to-peer lenders will fail, lufax's gibb says," Bloomberg Business, April 15, 2015.

[13] China: Online Payment Transaction Volume 2019| Statistic. Statista. [Online]. Available: http://www.statista.com/statistics/278524/online-paymenttransaction-volume-in-china/

[14] M. Porter, "The five competitive forces that shape strategy," Harvard Business Review, pp. 78-93, January 2008
[15] The Economist. (March 9, 2013). [Online]. Available: http://www.economist.com/news/leaders/21573104-interneteverything-hire-rise-sharing-economy

[16] S. J. Juliet, (October 2014). Debating the sharing economy. [Online]. Available:

http://www.tellus.org/pub/Schor_Debating_the_Sharing_Economy.p df

[17] Mind Tools, Editorial Team. (2016). [Online] Available:https://www.mindtools.com/pages/article/newTMC_09.ht $\mathrm{m}$

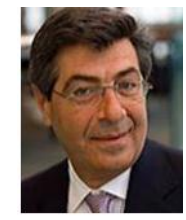

Reza Djavanshir got the doctor of science in systems engineering, and joined the Johns Hopkins Carey Business School in 2002. He is an Associate Professor with expertise in the areas of global sourcing and supply chains, technology transfer \& strategic planning, technology institutionalization, smart cities and smart infrastructures, information technology developments, and entrepreneurship strategies. 